\title{
Breeding status of tung tree (Vernicia sp.) in China, a multipurpose oilseed crop with industrial uses
}

\author{
By ZhiYong Zhan ${ }^{1), 3)}$, YangDong WAnG $^{1), *)}$, J. Shockey ${ }^{2)}$, YiCun Chen ${ }^{1)}$, \\ ZhiChun ZHou ${ }^{1)}$, XIAOHuA YAO ${ }^{1)}$ and HuADong ReN ${ }^{1)}$
}

(Received 28 $8^{\text {th }}$ May 2012)

\begin{abstract}
As a developing country with the world's largest population, China faces a serious challenge in satisfying its continuously increasing energy demands. Tung trees (Vernicia sp., especially V. fordii and V. montana), are multipurpose, perennial plants belonging to the Euphorbiaceae family. The unique chemical properties of tung seed oil make it one of the best known industrial drying oils. In this review, the breeding status of tung trees in China and some factors which limit the development of tung tree breeding will be summarised. Improvements in ecological performance and pathogen resistance, through to improved breeding methods, will help to rapidly expand the development and use of tung trees and their oil products in China. It is essential for tung tree breeding to advance in the future to keep pace with the increased demand.
\end{abstract}

Key words: Tung tree; Vernicia spp.; eleostearic acid; bio-energy; cross-breeding.

\section{Introduction}

As a developing country, industry in China has developed rapidly since the implementation of reform policies in 1970, and because of this, the demand for energy in China has increased dramatically. The Global Times pointed that in the end of 2009, China exceeds US to become Saudi Arabia's top oil customer (http:// www.globaltimes.cn/business/china-economy/2010-02/ 507404.html) and had become the largest oil market in the world. To meet the increasing demand for petroleum products, more than 200 million tons of crude oil and oil products (approximately 52\% of global market) was imported to China in 2008 (FANG et al., 2009). Such a high level of dependence on oil imports could threaten the stability of the Chinese economy and society (YIN and LIU, 2006). Therefore, petroleum substitutes must be developed in China to address this important issue. The government has devoted large amounts of money to develop the bioenergy industry. Bioenergy contributes a significant share of global primary energy consumption and its importance is likely to increase in future world energy scenarios (VASUDEVAN et al., 2005).

\footnotetext{
1) Research Institute of Subtropical Foresty, Chinese Academy of Foresty, Fuyang 311400, China.

2) United States Department of Agriculture-Agricultural Research Service, Southern Regional Research Center, New Orleans 70124, LA, USA.

3) First author: ZHIYong ZHAN. E-Mail: zhanzhiyong862007@hotmail.com

*) Corresponding author and Co-first author: YANGDong WANG. Tel.: +865716310 5072; Fax: +865716332 7982 . E-Mail: wyd11111@126.com
}

Tung (Vernicia fordii H., previously classified as Aleurites fordii) oil, extracted from tung tree seeds, contains $80 \%(\mathrm{w} / \mathrm{w}) \alpha$-eleostearic acid, a conjugated trienoic 18-

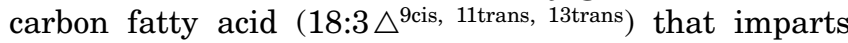
useful drying and blending properties to the oil (SonNTAG, 1979). Tung oil is currently used in paints, highquality printing, plasticisers, and in certain types of medicines and chemical reagents (PARK et al., 2008; SHANG et al., 2010; CHEN et al., 2010a).

The tung tree is a multipurpose perennial plant belonging to the genus Vernicia. Tung is adaptable to several soil types, provided that proper drainage and aeration conditions are met (POTTER, 1959). Tung begins to flower approximately three years after planting. Most flowers are monoecious, but small percentages are dioecious. Tung trees in China typically flower time from late April to early May, (approximately 15 days). Flower petals range in number from 4-9 and they are white tinged with red and yellow, darker at the base with dark red-branched lines running lengthwise. Individual tung fruits typically contain multiple (usually 4-5) seeds surrounded by a thick verrucose seed coat. Seeds contain approximately $50-70 \%$ oil by weight. Seeds are harvested at the end of October, having reached the maximum oil content. Many tung tree species are native to China, which has a long history of tung tree plantations, which collectively produce about 80,000 tons of oil per year, or about $70-80 \%$ of the world market (CHEN et al., 2010a). However, the output of tung oil in China still will not meet the projected requirements of the international market in future years. The ultimate objective of the tung tree breeding program in China is to create a new hybrid species or find improved varieties with enhanced oil yield and quality. This paper summarises the current status of tung tree breeding, and provides a critical analysis that will assist in the development of new and improved breeding strategies in China.

\section{Breeding status}

\subsection{Genetic resources}

To assist in future breeding plans, comprehensive efforts have been undertaken to collect, analyse and classify the variety of tung tree genetic resources (SHEN, 1994). Tung tree plantations have been developed for thousands of years, dating from the Han dynasty. Over this length of time, China has developed abundant natural tung tree varieties (Table 1). In the 1980s, China started to collect and conserve the tung tree germplasm, and constructed 5 gene banks (LING et al., 1991) to protect the species diversity. These gene banks are located 
in Guizhou, Hunan, Zhejiang, Guangxi and Henan provinces to facilitate the provision of these materials to the other provinces as needed. Tung tree cultivars from Zhejiang and Guangxi provinces have been compared recently in Fuzhou of Jiangxi province. The results showed that the cultivars from Guangxi outperformed those from Zhejiang due to higher oil yield, stronger fruiting potential and better overall growth (ZHOU et al., 1993).

\subsection{Species selection}

Plant traits which directly affect oil production can be simply named superior traits. Oil yield, oil quality and biotic/abiotic stress resistance are the most important superior traits in tung tree breeding (Table 2). Improved varieties are those cultivars which have some of these superior traits. The focus of cultivar selection is to find improved varieties from among all available natural germplasm, using certain testing methods. The selection process is quite slow, and achievements in finding improved varieties have been rare. The main tung species used in China today still lack some superior traits, which ultimately results in a loss of oil yield and a failure to fulfill the needs of the tung oil market.

In 1985, researchers constructed a tung tree plantation in Hunan province that contains 50 clones bearing superior traits relative to the indigenous cultivars. Of these clones, four showed a two-fold increase in the yield of individual fruit (HE et al., 1991). Factors such as pri- mary stem and secondary stem quality, fruit yield and oil yield can be used to study relationships between growth and oil output in tung trees. CHEN (1998) measured these factors in 69 clones and classified them into four groups relative to the oil output of the control sample. The average oil output percentages were $238.6 \%$, $187.7 \%, 112.3 \%$ and $56.1 \%$ of the control asexual sample, respectively. Other researchers (WANG and SoNG, 1992) identified superior clones which average $67 \%$ higher yield of fruits than the control, after testing the fruit yield, and fruit, stem and oil quality.

\subsection{Asexual Propagation}

The degree of genetic variation in tung trees is higher than in other species from the Vernicia genus because of increased occurrences of natural hybridization (FANG and $\mathrm{HE}, 1998)$. This process results in gene segregation and gene recombination between generations and brings about character segregation. Character segregation greatly reduces the yield of tung oil from earlier generations of previously improved varieties. Asexual propagation is frequently used to minimise this problem ( $\mathrm{LI}$ and FENG, 2005).

Graft breeding and tissue culture are the main technologies used in asexual propagation of tung tree. Experiments conducted at the Chinese plantations show that interspecies grafts within the same genus are often successful. Grafts among species are not only helpful in improving fruit yield, oil quality and stress resistance,

Table 1. - Comparison of key oil production traits of Chinese tung tree cultivars.

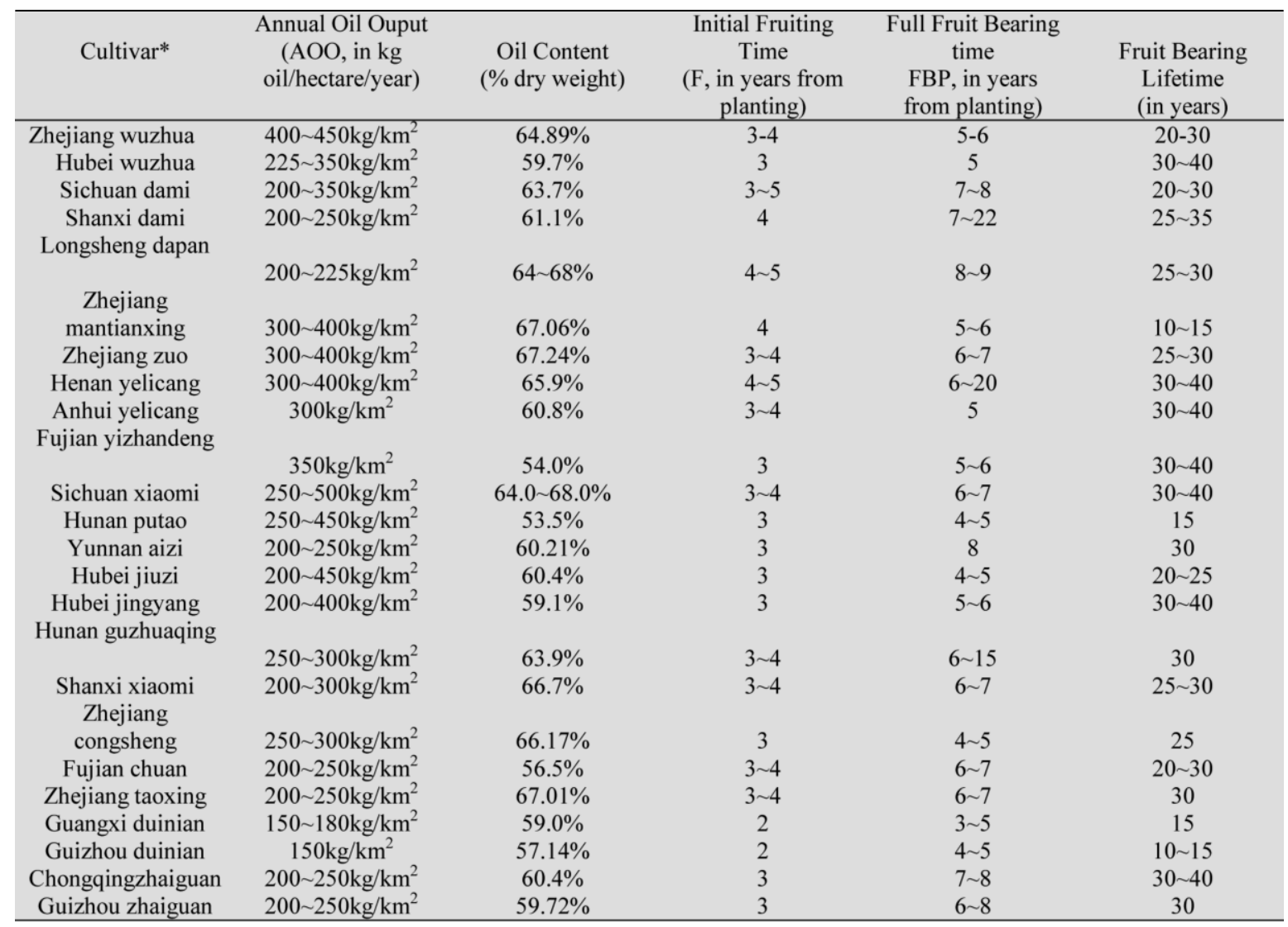

* All cultivars described belong to Vernicia fordii. 
Table 2. - The superior traits desired in an improved tung tree variety.

\begin{tabular}{|c|c|c|}
\hline $\begin{array}{l}\text { Considered } \\
\text { parts }\end{array}$ & Characters & References \\
\hline Stem & $\begin{array}{l}\text { The primary stem is straight and the arrangement of secondary } \\
\text { branches is amenable to fruit development. }\end{array}$ & $\begin{array}{l}\text { Shi et al. 2010; Zong et al. } \\
\text { 2010; Wan et al. 2010; Weng } \\
\text { et al. } 2010\end{array}$ \\
\hline Fruit & $\begin{array}{l}\text { The fruit is big and contains maximum number of seeds per fruit. } \\
\text { The fruiting period starts earlier and lasts longer. The annual fruit } \\
\text { yield is high }\left(\geq 500 \mathrm{~kg} / \mathrm{km}^{2}\right) \text {. }\end{array}$ & $\begin{array}{l}\text { Liu et al. 2011; Wu et al. 2011; } \\
\text { Peng et al. 2010; Zhu et al. } \\
2011\end{array}$ \\
\hline Oil & $\begin{array}{l}\text { Oil content (as a percentage of dry weight) and oil quality } \\
\text { (generally a function of eleostearic acid content) is increased. }\end{array}$ & $\begin{array}{l}\text { Li et al. 2009; Wang et al. } \\
\qquad 2009\end{array}$ \\
\hline Resistance & $\begin{array}{l}\text { Trees demonstrate high adaptability to biotic and abiotic stresses } \\
\text { (including temperature and water deficit stress and challenges } \\
\text { from diseases and insect pests). }\end{array}$ & $\begin{array}{l}\text { Zhang et al. 2011; Xu et al. } \\
\text { 2011; Fang et al. } 2011 \text {; Ge et } \\
\text { al. } 2011\end{array}$ \\
\hline
\end{tabular}

but also can reduce age to maturity. Graft compatibility and graft timing are the major factors that affect graft survival. The survival rate is different between different combinations of rootstocks and scions. A previous study compared the survival rates of different combinations of Dami $\times$ Xiaomi and Aleurites montana $\times$ Aleurites fordii; results showed that the survival rate in the combination of Dami $\times$ Xiaomi was higher (WANG and XIONG, 2006). Graft timing significantly affects the survival rate. The optimal time for grafting in tung trees is March to April (TAN, 1987) due to the sufficient soil hydration and temperatures compatible for cambium cell action. The technology of tissue culture also can be successfully applied to tung tree clone production. The reported survival rate of plants generated by tissue culture has recently surpassed 85\% (ZHANG et al., 2009).

\subsection{Analysis of potential parental lines for cross-breeding}

Currently, the study of tung tree cross-breeding in China is not advanced, and a new objective of crossbreeding studies is the selection of crossing parents. Good combinations of crossing parents are helpful in enhancing the quality and yield of tung oil. WANG (2002) found that tung tree plantations which contained some cross-pollinated trees were more economical than the plantations which did not plant cross-pollinated trees. Twenty cross-pollination combinations were chosen for production after this study. Previous studies analysed the general combining ability (GCA) and special combining ability (SCA) of certain characters, including the ratio of female and male flowers and the fruit yield per individual tree, using progeny derived from cross-bred lines from five local cultivars from Hunan, Hubei, Sichuan and Zhejiang provinces. The results indicated that differences in GCA were significant at the $1 \%$ level, while the SCA differences were not significant ( $\mathrm{LI}$ et al., 1988). These data may be useful in choosing additional parental lines for the next generation of cross-breeding strategies.

\subsection{Resistance breeding}

Black spot (GUO, 1992), anthracnose (CAO, 1988) and blight (HUA, 1991) are the main diseases in tung trees, and the main insect pests are longicorn beetle, scarab and stinkbug (CHEN et al., 2005). Both disease and insect pests reduce the yield of tung oil. It is necessary to develop resistance breeding programs in tung trees, as another method to improve the yield and export of tung oil. A correlation exists between black spot disease and free amino acid content in tung trees (XU et al., 1998). Trees containing reduced free amino acid content are more easily infected by black spot. Maintenance of high free amino acid levels results in healthy tung trees. This conclusion is supported by studies of other plants by RUDGARD and WHEELER (1985) and now it has become a test index to measure the resistance against black spot at the seedling stage. HUA (1991) isolated two clones with high blight resistance several years of in-depth study. Studies of root rot in tung trees (primarily caused by Clitocybe tabescens), recognised that proper maintenance of soil conditions is the most effective way to control this disease. High temperature, excessive soil moisture and alkaline $\mathrm{pH}$ were the main critieria that led to increased rates of root rot infections (CHEN and XIAO, 1990).

\subsection{Promotion and preservation of improved varieties}

After the work of species selection is successful, the improved varieties and superior clones must be planted widely in China to enhance the yield of tung oil. Promoting widespread use of newly developed germplasm is often the most effective method of preserving it. Superior clones named Yu1, Yu2 and Yu3 from Henan province possess high yield, and improved stability and oil quality. The output of tung oil in Henan increased $40 \%-70 \%$ after substantial planting of these clones (LIU et al., 1996). Many of the tung tree plantations in Hunan province consist of improved varieties or superior clones; recent yields from these plantations have increased over 
longer term averages as well. The trees in Guangxi have been particularly successful, having recently returned the highest yields in this provinces' history (LING, 1993). Guangxi province constructed the first cutting orchard which contained 28 well-recognised superior clones in 1983 (LING, 1993).

\section{Limiting factors}

\subsection{The lack of efficient breeding resources}

The direct effect of efficient breeding resources on the development of improved varieties of tung trees in China began many years ago. Results indicated that an acceleration of development of efficient breeding resources was a necessity (SHEN, 2010a). The 1960s were a period of great development of the tung tree industry in China, due to the recognition of tung oil as a major agricultural commodity. Many of the programs for developing tung tree stocks that were initiated then made use of breeding resources and practices that were sufficient at that time. But later, as the price of tung oil in the world market decreased and the policy for developing tung trees changed, a great number of tung plantations were cut down by farmers. After years of effort, traditional breeding methods have led to an increase in tung tree germplasm diversity again, but modern tools and resources for efficient breeding are still scarce. It is therefore necessary to accelerate the development and implementation of efficient breeding resources in tung trees.

\subsection{The low breeding efficiency}

In past years, the selection of improved varieties and superior clones had focused on the selection of economically-valuable traits by traditional breeding methods. Traditional breeding programs have historically only emphasised the maximisation of economic benefits, without considering ecological benefits. Like many other trees, tung plantations can provide protect and enhance the local environment (such as by reducing hillside erosion and providing habitats for wildlife), if the cultivars are carefully chosen to be well-suited for the typical climate and soil (CATER et al., 1998). The use of gene variations and the interaction between genotype and environment were often ignored in breeding programs of the past. These traditional breeding methods have fallen behind because breeding methods do not make full use of the power and flexibility of modern biotechnology ( $\mathrm{HU}$ et al., 2004). Collectively, these challenges have lead to low tung tree breeding efficiency despite the 40 year history of this project.

\section{Some suggestions for improvement}

\subsection{Enlarging the breeding resources}

New tools and genetic information are the bases for the development of efficient breeding resources (SHEN, 2010a). The level of effectiveness of these resources directly impacts the breeding result. The lack of effective breeding resources is the primary cause for the industry-wide gaps between theoretical and actual yields in tung oil quantity and quality. The promotion of improved varieties must abide by laws that require matching tree species with the proposed growing site, which allows the improved varieties to make full use of its potential production, while reducing the risk of negative unintended ecological outcomes (CATER et al., 1998; SHEN, 2010b). New breeding resources, including the creation of artificial breeding resources (MA, 1993; XIAO et al., 1996), are now under development.

\subsection{Development of ecological breeding strategies}

Trees can reach their potential production only if optimally suited to their environmental conditions (SHEN, $2010 \mathrm{~b})$. In the past, general comparative geographical analyses were the major determinants for estimation of environmental adaptability and subsequent species selection. Overlooking local environmental characters can cause serious misinterpretation of the data from these comparative experiments. Therefore, understanding and development of ecological breeding characters has since become a major point of emphasis in various forestry projects, including those dedicated to tung (LIU, 2007). The basis of ecological breeding is similar to the selective pressure from nature. The selective pressure helps to select species or cultivars with the best adaptability to environmental challeges. Specifically, tung plantations must consist of species with the best adaptability not only for maximal oil production, but also for best protection of the local soil ecology and least amount of soil erosion. Ecological benefits and economic benefits should be considered to the same degree.

\subsection{Continued development of resistant clones and culti-} vars

China observes frequent breakouts of tung tree disease and insect pests, resulting in large economic losses. At present, the achievements in resistance breeding are insufficient to reliably protect against such losses. Improvements in resistance have been achieved for only a few insect pests and diseases, and better resistance is necessary to reduce and stabilise the loss potential. Enlarging the number of breeding resources and other related tools can solve this problem. Secondly, the genetics of the trees' resistance to diseases and insect pests should be studied more intensively (XIAO and CHYE, 2011).

\subsection{Development of improved breeding methods}

Distant hybridization is an effective method to generate a new genetic variation. The oil content of Ricinus is higher than in Jatropha curcas (SUJATHA et al., 2008; SunIL et al., 2008), however, these two plants are closely related in the Euphorbiaceae family. Thus, it is possible that a new genetic variation of Jatropha curcas will be generated by distant hybridization with Ricinus. Additionally, marker-assisted selection breeding is another effective method can help us to improve the breeding efficiency. The genetic relationships of Jatropha curcas from various countries have been analysed by random amplification of polymorphic DNA (RAPD) and inter-simple sequence repeat (ISSR). The results indicated the Mexico contains a rich diversity of J. curcas germplasm (BASHA et al., 2009), suggesting 
that other breeding resources of Jatropha curcas can be improved by germplasm penetration. Expressed sequence tag (EST) sequencing technology was used to identify important genes controlling fatty acid biosynthesis in J. curcas; these genes were cloned and will be used to improve germplasm quality and diversity by genetic transformation (LiN et al., 2003). Also, the advancement of modern biotechnology provides a good opportunity for tung tree breeding. Biotechnology, especially transgenic technology (LI et al., 2011; WANG and ZHANG, 2011), radiation-mutation breeding (YI et al., 2010), and space breeding (OUYANG and GUO, 2010) could help researchers gain access to new gene variations. Essential tung oil biosynthetic genes have been identified and cloned successfully (XU et al., 2011a; CHEN et al., 2010b; LI et al., 2008a; SHOCKEY et al., 2006). In addition, the genetic relationships among the different tung cultivars in China were analysed by ISSR (LI et al., 2008b) and microsatellite markers (XU et al., 2011b). Such basic research on the molecular level of tung tree will lay a solid foundation for molecular breeding development. Improving the breeding methods and production will very likely require combining traditional breeding methods with modern biotechnology.

\section{Conclusion}

We summarised here the breeding status of tung trees in China including the species resources, the status of asexual propagation, cross-breeding and resistance breeding. In this review, we also provided analysis of some factors that have limited the development of breeding and gave some suggestions for strategies that may enlarge the breeding resource diversity.

\section{Acknowledgements}

This work was supported financially by Special Fund for Forestry-scientific Research in the Public Interest (200904042).

\section{References}

Basha, S. D., G. Francis and H. P. S. MakKar et al. (2009): A comparative study of biochemical traits and molecular markers for assessment of genetic relationships between Jatropha curcas L. germplasm from different countries. Plant Science 176(6): 812-823.

CAO, J. (1988): A study on the anthracnose of tung tree. Forest Pest and Disease 1: 4-5.

Carter, C., L. House and R. Little (1998): Tung oil: a revival. Rev. Agric. Econ. 20: 666-673.

Chen, F. (1998): Study on the Selection of 69 Asexual Tung Tree Families by Canonical Correlation Analysis. Forest Research 11: 518-522.

Chen, P., D. Wang and R. BAI (2005): Main Pests and Disease of Aleurites fordii in Yunnan. West China Forestry Science 34: 79-82.

Chen, S. and Y. XIaO (1990): Studies on the Epidemic and Forest of Root-Rot Tung Tree. Forest Research 26: 219-225.
Chen, Y., J. Chen, C. Chang and C. Chang (2010a): Biodiesel production from tung (Vernicia montana) oil and its blending properties in different fatty acid compositions. Bioresource Technology 101: 9521-9526.

Chen, Y., G. Zhou, Y. WANG and L. Xu (2010b): F-Box and oleosin: additional target genes for future metabolic engineering in tung trees? Industrial Crops and Products 32: $684-686$.

FAnG, J. and F. HE (1998): Tung trees in China. China Forestry Publishing House, Beijing.

FANG, X., Y. SHEN and J. ZHAO (2009): Status and prospect of lignocellulosic bioethanol production in China. Bioresource Technology 101: 4814-4819.

Guo, W. (1992): A Study on the Physiological and Biochemical Mechanisms of Tung Oil Tree Varieties Resisting Black Spot. Fujian College of Forestry 12: 29-35.

HE, F., X. TAN and C. WANG (1991): Selective breeding of clonal on tung oil trees. Journal of Central-South Forestry College 11: 120-124.

HuA, S. (1991): Studies on the Selection and Appraisal of Blight-disease-resistant Families of Aleurites fordii. Forest Research 4: 160-166.

Hu, J., Z. WANG, Y. Li and J. LiU (2004): General Situation and Development Direction of Sweet Corn Breeding in China. Journal of Maize Sciences 12: 12-15.

LI, P., X. Zhang, Y. Chen and Y. WANG (2008b): Genetic diversity and germplasm resource research on tung tree (Vernicia fordii) cultivars, investigated by inter-simple sequence repeats. African Journal of Biotechnology 7(8): 1054-1059.

LI, S., X. Su and B. Zhang (2011): Research Progress in Gene Cloning in Forest Trees. Chinese Bulletin of Botany 46: 79-107.

LI, Y. and D. FENG (2005): Advances in Research into Polyploidy Breeding of Woody Plants. Chinese Bulletin of Botany 22: 375-382.

LI, Y., Y. WANG and P. Li et al. (2008a): Study on the cloning and sequence analysis of FADX gene from Vernicia fordii. Journal of Anhui Agri. Sci. 36(11): 4753-4755.

LI, Z., X. WANG and G. SHI (1988): The analysis on the tung tree's main traits GCA. Genetics 10: 11-14.

LIN, J., Y. LI and X. ZHOU et al. (2003): Cloning and characterization of a curcin gene encoding a ribosome inactivating protein from Jatropha curcas. DNA Sequence 14(4): 311-317.

LING, L. (1993): Evaluation on the genetic improvements and benefits of tung oil trees in Guangxi. Economical Forest Researches S1: 189-195.

LING, L., B. QIN, D. YAN, J. LIN and N. ZHANG (1991): Study on the gene banks and improved genes of tung oil trees. Guangxi Forestry Science 1: 54-57.

LiU, C., Y. WANG, J. Li and C. FAN (1996): The selective breeding of 3 improved families on the species of tung trees of "Yu Tong". Economical Forest Researches 14: $45-47$.

LIU, H. (2007): Strengthen Improved Tree Species for Modern Forestry Construction. Forestry Economics 8: 25-29.

MA, C. (1993): Some New Ideas on Genetical Improvement of Forest Trees. World Forestry Research 2: 13-22.

Ouyang, L. and J. Guo (2010): Preliminary Study on the Changes of Restoring Abilities of Restoring Line of Three Lines Rice by Space Mutation. Chinese Agricultural Science 26: 75-79. 
PARK, J., D. KIM and Z. WANG (2008): Production and characterization of biodiesel from tung oil. Appl. Biochem. Biotechnol. 148: 109-117.

PotTer, G. (1959): The domestic tung industry. I. Production and improvement of the tung tree. Econ. Bot1 3: $328-342$.

RUdGARD, S. and B. WheELER (1985): The development of Erysiphe cruciferarum on field-grown brussels sprouts and associated changes in soluble amino acids in leaves. Plant Pathology 34: 616-625.

Shang, Q., W. Jiang, H. Lu and B. Liang (2010): Properties of tung oil biodiesel and its blends with 0\#diesel. Bioresource Technology 101: 826-828.

Shen, X. (1994): Talking about the Forest Tree Breeding Work in Fujian Province from the Advances of Forest Tree Breeding at Home and Abroad. Journal of Fujian Forestry Sci. \& Tech. 21: 8-12.

SHen, X. (2010a): On the Construction China's Forests Thoroughbred base. Forestry Economics 7: 48-51.

SHEN, X. (2010b): The status and develop suggestions on China's forests thoroughbred base. China Forestry Science and Technology 24: 1-3.

Shockey, J. S., S. GiddA and D. Chapital et al. (2006): Tung tree DGAT1 and DGAT2 have nonredundant functions in triacylglycerol biosynthesis and are localized to different subdomains of the endoplasmic reticulum. Plant Cell 18(8): 2294-2313.

SonNTAG, N. (1979): Composition and characteristics of individual fats and oils. In Bailey's Industrial Oil and Fat Products 1: 289-477.

Sujatha, M., T. P. Reddy and M. J. MAHASI (2008): Role of biotechnological interventions in the improvement of castor (Ricinus communis L.) and Jatropha curcas L. Biotechnology advances 26(5): 424-435.

SuniL, N., K. S. VARAPRASAD and N. SivARAJ et al. (2008): Assessing Jatropha curcas L. germplasm in-situ A case study. Biomass and Bioenergy 32(3): 198-202.

TAN, F. (1987): The basic study about the survive laws of clones grafting on tung oil trees. Economical Forest Researches 5: 91-94.

VASudevan, P., S. Sharma and A. Kumar (2005): Liquid fuel from biomass: an overview. J. Sci. Ind. Res. 64: 822-831.

WANG, C., F. HE, F. Lin, Z. Gu and Z. Du (2002): Determination of the Pollen Cooperation of Tung Oil Tree and
Analysis of Its Yield Genetic Effect. The journal of Central South Forestry University 22: 40-43.

WANG, C. and J. Song (1992): Selective breeding of improved family on tung oil trees in Hunan province. Economical Forest Researches S1: 66-73.

Wang, C. and G. XIONG (2006): Research of grafting breed technique of Tung tree. The Journal of Hunan Forest Sci. \& Tech. 33: 30-32.

Wang, Z. and F. ZHANG (2011): Advances and Application of Transgenic Technology in Cotton Breeding 2: 12-17.

XIAO, S. and M. CHYE (2011): Overexpression of Arabidopsis Acyl-CoA-Binding Protein 3 Enhances NPR1-Dependent Plant Resistance to Pseudomonas syringe pv. tomato DC3000. Plant Physiol. June 13, PMID: 21670223

XIAO, S., G. ChEN and Z. LIN (1996): Present Situation and Countermeasures of the Collection, Preservation and Utilization of Forest Tree Germplasm Gene Resources. Journal of Fujian Forestry Sci. \& Tech. 23: 18-21.

Xu, F., M. Ge, Z. ZhaO and K. Zhu (1998): Studies on the Relationship of Amino Acid Content of Different Masson Pine Provenances and Their Resistance to Pine Wood Nematode (PWN). Forest Research 11: 313-318.

XU, L., Y. WANG, Y. CHEN and G. ZHOU (2011a): Cloning of tung tree DGAT2 gene and construction of RNAi binary expression vector with convergent promoters. Forest research 24(5): 668-673.

XU, W., Q. YANG, H. HuAi and A. LiU (2011b): Microsatellite marker development in tung trees (Vernicia Montana and $V$. fordii, Euphorbiaceae). American Journal of Botany 98: e226-e228.

Yi, W., W. Peng, X. Peng, W. Tu and B. Pang (2010): Development and Prospect of Radiantion-mutation Breeding of Rice Century in Hunan Province. Hunan Agricultural Sciences 7: 1-3.

YIN, J. and D. LIU (2006): Strategic thinking on developing petroleum substitutes in China. Petroleum Sci. 3: 46-51.

Zhang, S., Y. Chen and Y. WANG (2009): Tissue Culture and Rapid Propagation of Vernicia fordii (Hemsl.) Plant Physiology Communication 45: 1008.

Zhou, Z., M. WANG and Q. Li (1993): The study on the comparative experiments of tung trees good species. Forest Science of Jiangxi 10: 20-22. 